\title{
Ambiente receptivo uterino: control materno, control embrionario, muerte embrionaria
}

\section{Receptive uterine environment: maternal control, control embryo, embryonic death}

\begin{abstract}
Ángela Gonella D, ${ }^{1 *}$ MVZ, Henry Grajales L, ${ }^{2}$ Ph.D, Aureliano Hernández V, ${ }^{3}$ Ph.D.
${ }^{1}$ Universidad Nacional de Colombia, Facultad de Medicina Veterinaria y de Zootecnia, Grupo de investigación en Fisiología de la Reproducción. Bogotá, Colombia. ${ }^{2}$ Universidad Nacional de Colombia, Departamento de Ciencias para la Producción Animal, Facultad de Medicina Veterinaria y de Zootecnia.Bogotá, Colombia. '3Universidad Nacional de Colombia, Departamento de Ciencias para la Salud Animal, Facultad de Medicina Veterinaria y de Zootecnia. Bogotá, Colombia.*Correspondencia: amsaavedrag@unal.edu.co
\end{abstract}

Recibido: Febrero 3 de 2009; Aceptado Agosto 20 de 2009.

\section{RESUMEN}

El ambiente receptivo en el útero, o ambiente embriotrófico, se define como la capacidad del organismo materno para hospedar el conceptus exitosamente. La receptividad uterina depende de la correcta sincronía del eje conceptus - cuerpo lúteo - endometrio y está controlada por dos mecanismos. El primero depende de la madre y se establece a través de las relaciones entre los estrógenos $\left(E_{2}\right)$ y la Progesterona $\left(P_{4}\right)$. El segundo es mediado por el trofoblasto que secreta interferón Tau (INFt). Los estrógenos se sintetizan en las células foliculares y determinan los cambios fisicoquímicos, morfológicos y del comportamiento expresadas por la hembra durante el celo. La $\mathrm{P}_{4}$ es sintetizada por el cuerpo lúteo (CL), y promueve, entre otros, cambios a nivel endometrial para la manutención de la gestación. Cuando la fertilización y desarrollo embrionario son exitosos, el INFt ejerce su efecto luteotrópico entre los días 15 y 19 de la gestación, desencadenando el proceso de reconocimiento materno para evitar la regresión luteal y asegurar la sobrevivencia del embrión. Además, el INFt estimula al organismo materno para producir un microambiente que le provea al embrión condiciones nutricionales, inmunológicas y fisiológicas óptimas para su desarrollo. La presente revisión pretende contextualizar cuales son los cambios que sufre el endometrio para proveer las condiciones necesarias permitiendo que el embrión se desarrolle correctamente y se establezca una gestación.

Palabras clave: Útero, progesterona, estradiol, proteínas de la gestación, muerte embrionaria. 


\section{ABSTRACT}

The receptive environment on the uterus, or embryotrophic environment, it is the mother's capacity to successfully hostel the conceptus. The uterus receptivity depends on the correct synchrony of the conceptus - corpus luteum - endometrium axis and it is controlled by two mechanisms; the first one is controlled by the mother through the relationship between estrogens (E2) y progesterone (P4); The second one is mediated by the trophoblast through the secretion of interferon tau. The estrogens are synthesized in the follicular cells and modulate physical, morphological and behavioral changes during the female hit. P4 is synthesized by the corpus luteum and one of its functions is to promote the gestation's maintenance. When fertilization and embryo development is successful the INFt exert its luteotrhopic effects between 15th and 19th days of gestation, unchaining mother's recognition of gestation process to avoid the luteal regression and to guarantee the embryo survival. Besides, the INFt stimulate the mother's organism to produce a microenvironment that provides optimal nutritional, immunological and physiological conditions to embryo. This review wants to contextualize the endometrial changes that provide the necessary conditions for the embryo development and the established of the gestation.

Key words: Uterus, progesterone, estradiol, pregnancy proteins, embryo loss.

\section{INTRODUCCIÓN}

Los procesos por los cuales el embrión logra sobrevivir en el útero son de gran complejidad y de su culminación adecuada depende en parte el éxito de las empresas pecuarias. Aún falta mucho por conocer acerca de su naturaleza, funcionamiento y cómo se podría lograr una mayor eficiencia reproductiva al disminuir la mortalidad embrionaria, la cual es una importante limitante. El ambiente receptivo en el útero, o ambiente embriotrófico, es la capacidad del organismo materno para hospedar el conceptus exitosamente. La receptividad uterina depende de la correcta sincronía del eje conceptus-cuerpo lúteo-endometrio (1). Está controlada por la madre a través de las relaciones entre los estrógenos $\left(E_{2}\right)$ y la Progesterona $\left(\mathrm{P}_{4}\right)$; y por el trofoblasto mediante la secreción de interferón Tau (INFt). Los estrógenos se sintetizan en las células foliculares del ovario y determinan los cambios fisicoquímicos, morfológicos y del comportamiento expresadas por la hembra durante el celo. La $\mathrm{P}_{4}$ es sintetizada por el cuerpo lúteo $(\mathrm{CL})$, y promueve la manutención de la gestación (2). Cuando la fertilización y desarrollo embrionario son exitosos, el INFt ejerce su efecto luteotrópico entre los días 15 y 19 de la gestación $(3,4)$, desencadenando el proceso de reconocimiento materno de la gestación para evitar la regresión luteal y asegurar la sobrevivencia del embrión (5). Además, el INFt estimula al organismo materno para producir un microambiente que le provea al embrión condiciones nutricionales, inmunológicas y fisiológicas óptimas para su propio desarrollo (6).

\section{CONTROL MATERNO DE LA RECEPTIVIDAD UTERINA.}

La mayor liberación de la hormona luteinizante ("pico" de LH) induce la ovulación y posterior luteinización del folículo dominante (2), que da lugar a la formación de un cuerpo lúteo que debe ser capaz de producir niveles de $\mathrm{P}_{4}$ adecuados para que se establezca un ambiente receptivo en el útero (7). Sin embargo, para que la $\mathrm{P}_{4}$ pueda ejercer su función, debe darse una previa sensibilización por parte de los estrógenos durante la fase folicular (5) que determinan un aumento y una mayor permisividad de la permeabilidad vascular uterina permitiendo el paso al lumen uterino de proteínas, en especial la albúmina (8). Las hormonas esteroides al llegar al endometrio activan o desactivan la expresión de determinados genes, modificando así la síntesis de proteínas $(9,10)$. Algunos de ellos tienen mayor expresión durante el estro y otros durante 
el diestro (11), de manera que el correcto balance entre el $\mathrm{E}_{2}$ y la $\mathrm{P}_{4}$ determina que se de una condición adecuada del ambiente receptivo en el útero, al modificar la síntesis de proteínas en el endometrio (9). Las variaciones en los mecanismos de transcripción a mRNA y posterior traducción a proteína, conllevan los siguientes cambios que permiten el establecimiento de un ambiente embriotrófico:

Producción de leche endometrial. Las secreciones uterinas son necesarias para el crecimiento de los blastocistos, su migración, implantación y activación de su genoma (12). En los rumiantes, el conceptus está libre en el lumen uterino antes de la implantación y depende de la leche endometrial para su correcto desarrollo $(3,13)$. El control que ejerce la $\mathrm{P}_{4}$ sobre las secreciones uterinas ha sido corroborado por una gran variedad de experimentos, en donde se ha observado similitud de dichas secreciones en hembras cíclicas y preñadas hacia los mismos días postovulación $(9,10)$. Las proteínas de la leche endometrial son de vital importancia para el desarrollo del conceptus, pero se desconoce la función de muchas de ellas, fundamentalmente por la complejidad de la composición del proteoma (en las ovejas, está constituido por 2000-5000 polipéptidos) (13); porque varían según el momento del ciclo estral y/o, porque más del $50 \%$ de ellas son de origen plasmático (albúmina e inmunoglobulinas). Ante estas circunstancias, es difícil el estudio de las demás proteínas secretadas por el útero (14). Hay algunas de ellas identificadas, como la uteroferrina y la proteína unida al retinol (RBP), que, en su orden, son fuente de hierro y retinol para el conceptus, la superfamilia de las serpinas y algunos factores de crecimiento (13).

Aumento de la permeabilidad vascular. Durante la fase folicular del ciclo estral, en virtud de los altos niveles de estrógenos plasmáticos, hay marcado aumento en la formación de nuevos vasos sanguíneos y paso de proteínas desde los capilares hacia la luz del útero (15). En ratonas de laboratorio ovariectomizadas sometidas a diferentes dosis de estrógenos exógenos, se indujo la elaboración del Factor de Crecimiento Vascular Endotelial (VEGF) y el Factor de
Permeabilidad Vascular (VPF), mitógenos de las células vasculares, promotores de la angiogénesis y el edema del tracto reproductivo durante la fase folicular (16). El VPF incrementa la permeabilidad microvascular, favoreciendo el paso de proteínas al lumen uterino (16). Aunque la acción de estos factores se da en los primeros días del ciclo estral, el aumento de proteínas séricas en el lumen, en especial de la albúmina, propiciaría el establecimiento de un $\mathrm{pH}$ endometrial adecuado para el desarrollo del embrión en la fase luteal (8). Durante ésta, los estrógenos provenientes de las ondas foliculares no ovulatorias (2), mantendrían dicho mecanismo, lo cual sería complementario a la acción de la $\mathrm{P}_{4}$, reforzando así la importancia de la relación e interacción entre $E_{2}$ y $P_{4}(1)$.

Modificación morfofisiológica del útero. A lo largo del ciclo estral, la $\mathrm{P}_{4}$ determina los cambios histológicos del útero (10). "Los estrógenos estimulan la vascularidad del endometrio durante el estro y aumentan la actividad muscular uterina, en tanto que la $\mathrm{P}_{4}$ provoca disminución de la motilidad y crecimiento de los epitelios de revestimiento y glandular del endometrio" (1). Los cambios morfológicos del útero debidos al control materno, se observan en todo el órgano, mientras que el conceptus los induce sobre la zona de preferencia para la implantación (8). El control materno se hace principalmente a través de la $\mathrm{P}_{4}$, la cual, en la fase luteal, inhibe la expresión de algunas moléculas de la familia de factores de crecimiento (VEGF, Factor de Crecimiento Epidermal y sus receptores específicos), que son normalmente estimulados durante la fase folicular por acción del estradiol. Por ende, durante la fase luteal disminuye el edema y aumenta la producción glandular del útero (16). Por acción del EGF hay un aumento en el tamaño y función de las glándulas endometriales (17). Díaz et al (1), encontraron que existe un aumento significativo en el desarrollo del epitelio durante la fase luteal del ciclo estral, además de una mayor actividad secretora.

El control materno del ambiente embriotrófico sucede normalmente en todos los ciclos estrales. Si no hay una señal de reconocimiento materno habrá lisis del CL y 
se dará inicio a un nuevo ciclo estral (6). Cuando termina el diestro, la oxitocina estimula la producción de prostaglandina $F_{2 \alpha}$ $\left(\mathrm{PGF}_{2 \alpha}\right)$ en el endometrio, principal molécula luteolítica en los rumiantes (18). Los mecanismos luteolíticos que se originan en el endometrio uterino requieren de una secuencia de efectos producidos por las hormonas $\mathrm{P}_{4}, \mathrm{E}_{2}$ y oxitocina, las cuales actúan a través de sus receptores específicos $(5,19)$.

Al iniciar el ciclo estral, las vacas en celo tiene máximos niveles plasmáticos de $\mathrm{E}_{2}$ debido a la presencia de un folículo ovulatorio o de De Graff, lo cual estimula la síntesis de receptores endometriales para $\mathrm{P}_{4}(\mathrm{PR})$, oxitocina (OTR) y para los mismos estrógenos (ER) (Figura 1) (20).

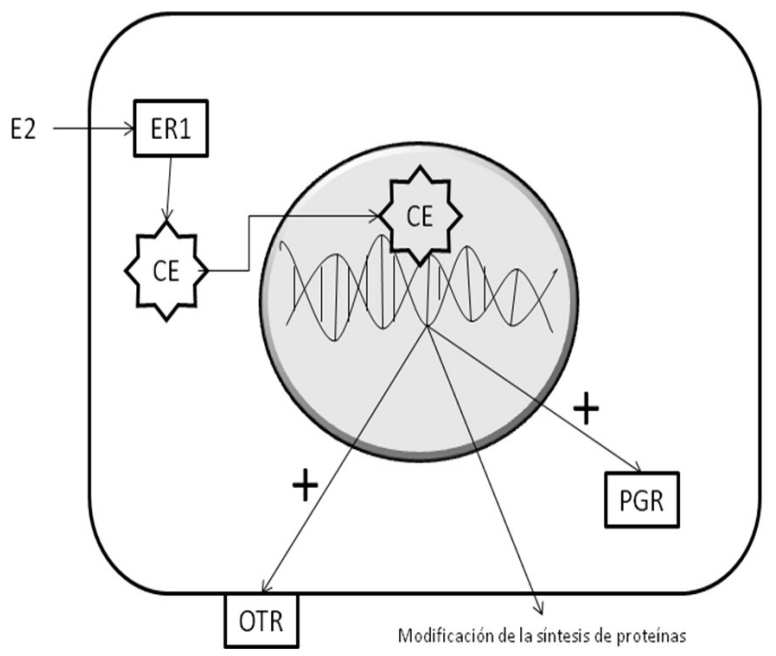

Figura 1. Durante la fase folicular, el estrógeno $\left(E_{2}\right)$ sintetizado por los folículos ováricos ejerce su acción en la célula endometrial al unirse a su receptor intracelular específico (ER1). La unión ligando - receptor conlleva al desencadenamiento de una cascada de señalización celular que permite la modificación en la actividad de factores de transcripción, los que se encargan a su vez, de modificar la expresión de genes determinados, dando como resultado una respuesta fisiológica. Dentro de estos cambios ejercidos por la acción del estrógeno en la célula endometrial, se encuentran: un aumento en la síntesis y expresión de receptores para $\mathrm{P}_{4}(\mathrm{PGR})$ y de oxitocina (OTR).
Durante el diestro aumentan los niveles séricos de $\mathrm{P}_{4}$ que inhibe la expresión de ER y OTR. Estas proteínas, según Spencer et al (5), no son detectables a partir del día 5 del ciclo estral y hasta los días 11 ó 12 . Aunque no se conoce el mecanismo por el cual la $\mathrm{P}_{4}$ realiza bloqueo en la expresión de los ER, hay quienes consideran que los OTR podrían ser inhibidos de manera secundaria a la inhibición de los ER (Figura 2) (21).

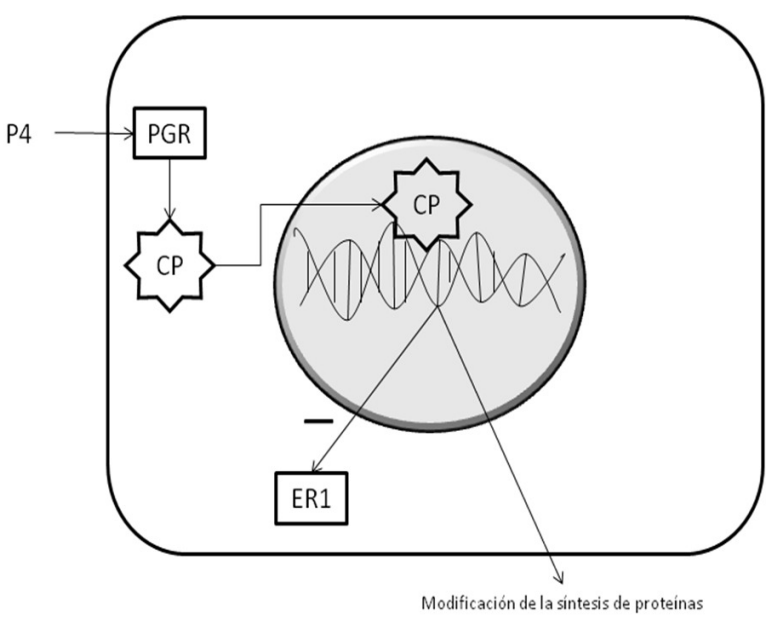

Figura 2. Luego de la ovulación, se da inicio a la síntesis de $\mathrm{P}_{4}$ (P4) por las células luteales. La $\mathrm{P}_{4}$ (P4) encuentra un buen número de sus receptores ( $P G R$ ) intracelulares en el endometrio, debido al estimulo previo ejercido por el estrógeno durante la fase folicular. La unión ligando-receptor desencadena una cascada de señalización que termina en la modificación de la expresión de ciertos genes, dando como resultado el "bloqueo de la $\mathrm{P}_{4}$ " sobre la expresión de receptores estrogénicos (ER1) y oxitocínicos (OTR).

La exposición prolongada de las células endometriales a la $\mathrm{P}_{4}$ (8-10 días) promueve la acumulación endometrial de acido araquidónico y cicloxigenasa (COX), lo cual es necesario para la síntesis de la PGF $_{2 \alpha}$ (20). Luego de varios días de exposición a la $\mathrm{P}_{4}$ (8-10 días), disminuyen notablemente los niveles endometriales de PR y aumenta la expresión de ER y OTR. Se considera que el proceso negativo de autorregulación ocurre por una disminución en la transcripción de genes que codifican para los PR (5). La oxitocina producida por la pituitaria posterior y las células grandes del $C L$ induce el inicio de los pulsos de $\mathrm{PGF}_{2 \alpha}$ en el endometrio, 
causando lisis del cuerpo lúteo $(2,19,20)$.

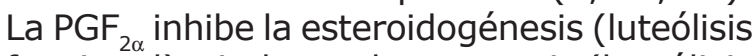
funcional) e induce a la apoptosis (luteólisis estructural), por lo que se da inicio a una nueva fase de proestro y por ende al inicio de un nuevo ciclo estral (Figura 3) (19).

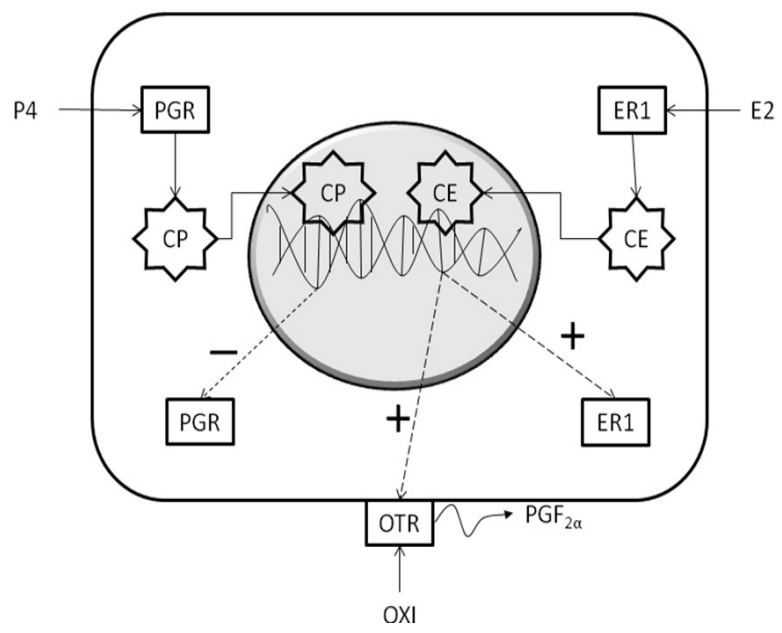

Figura 3. En la fase luteal tardía, en ausencia de una señal de reconocimiento materno, debe darse un proceso de luteólisis funcional para que se de inicio a un nuevo ciclo. El estímulo prolongado sobre la vía de señalización de la $P_{4}$ hace que se produzca una inhibición para la síntesis y expresión de PGR y un aumento en la síntesis de $\mathrm{PGF}_{2 \alpha}$. Lo que determina el inicio del proceso luteolítico.

\section{CONTROL EMBRIONARIO DE LA RECEPTIVIDAD UTERINA}

El control que ejerce el embrión sobre la receptividad uterina se inicia con la síntesis de INFt y el reconocimiento materno de la gestación. El conceptus viable en el útero debe ser capaz de interrumpir la ciclicidad reproductiva de la madre, promoviendo la acción de un $C L$ funcional que sintetice niveles adecuados de $\mathrm{P}_{4}(5,19)$. Durante la elongación rápida del blastocisto en los rumiantes, las células mononucleares del trofoblasto deben secretar cantidades crecientes de INFt, para el mantenimiento de la integridad morfológica y funcional del cuerpo lúteo, de manera que este sea capaz de mantener una producción continua y suficiente de $\mathrm{P}_{4}(22)$. Este efecto luteotrópico se produce inmediatamente antes del momento en el cual se da un incremento en la producción de PGF $_{2 \alpha}$ en vacas no preñadas, hacia el día $15-17$ del ciclo estral $(7,22)$. La secreción de INFt se inicia desde el día 7 y va hasta el día 30 de la preñez, sin embargo, es durante los días 15-19 donde ejerce su efecto lúteo-trópico $(3,4)$. Se han encontrado dos mecanismos de acción para el INFt: el primero consiste en prolongar el bloqueo de la $\mathrm{P}_{4}$ es decir, impide que se incremente la expresión de ER y $\operatorname{OTR}(21,23,24)$ debido a que estabiliza la síntesis y presentación de PR en el endometrio (23) y a que inhibe la enzima Prostaglandina H sintetasa-2 (Figura 4) (25). El segundo mecanismo estaría relacionado con la inhibición de receptores luteales para $\mathrm{PGF}_{2 \alpha}$. Esto fue demostrado en ovejas, a las que se les suministró PGF $_{2 \alpha}$ exógena luego de la señal de reconocimiento materno, con lo cual no se produjo luteólisis. Por esta razón, Niswender et al (18) y Roberts et al (7) aseguran que existe un mecanismo que inhibe la presentación de receptores para $\mathrm{PGF}_{2 \alpha}$ en el cuerpo lúteo. La naturaleza de dicho mecanismo aun no ha sido dilucidada.

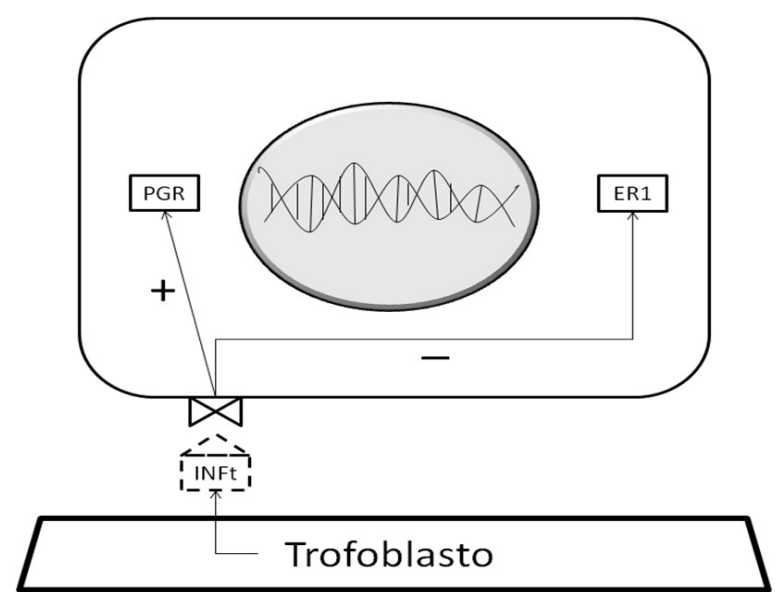

Figura 4. Si en la fase luteal tardía se da una señal eficiente de interferón tau (INFt), se inicia el proceso de reconocimiento materno. La unión de este a su receptor específico de membrana conlleva a la inhibición de la producción de prostaglandina $F_{2 \alpha}\left(P F_{2 \alpha}\right)$, de la síntesis de ER1 y al aumento en la expresión de PGR. Así como la modificación localizada del ambiente uterino para preparar al endometrio para que se lleve a cabo el proceso de implantación. 
Otra función del INFt es activar los mecanismos que modifican el medio ambiente uterino para que el conceptus lleve a cabo su desarrollo (23), a partir del estímulo de ciertos genes (ISGs: Interferon Stimulated Genes) en el endometrio $(11,26)$. Un ejemplo lo representan los genes WNT7A que codifican para una gran familia de glicoproteínas encargadas de regular el crecimiento y diferenciación celular para la implantación del conceptus y que se descubrieron al someter cultivos in vitro de células endometriales de ratón a un estímulo de INFt (27). Las principales acciones del INFt sobre el ambiente uterino, y que permiten el desarrollo normal de la preñez temprana son:

Modificación del fluido endometrial. Para lograr su óptimo desarrollo, al llegar al útero el embrión debe modificar la síntesis de proteínas. En un principio se creería que esta modificación consiste en el aumento de la síntesis proteica por parte del endometrio, pero en varios experimentos se comprobó que, por el contrario, la síntesis de proteína se disminuye bajo el estimulo del INFt (3, 10). El efecto del INFt consiste en modificar la síntesis proteica, y si bien la síntesis global de proteínas se ve disminuida, la de ciertas proteínas específicas aumenta considerablemente. En los experimentos realizados por Peiris et al (3) la síntesis de las proteínas de 40,45, 52, 62 y 70 kDa aumentó drásticamente luego del reconocimiento materno de la gestación. Los autores no identificaron dichas proteínas, pero actualmente se sabe que las proteínas estimuladas por el INFt consisten principalmente en factores de crecimiento, factores para la modulación del sistema inmune materno y factores y enzimas para la remodelación endometrial (27).

Modificación de la respuesta inmune materna. El INFt modifica el sistema inmune materno, para que éste no reconozca al conceptus como un antígeno. El trofoblasto presenta una variación en el complejo mayor de histocompatibilidad (28), de manera que no es reconocido fácilmente por la línea de defensa materna. Sin embargo, esta modificación no es suficiente y el conceptus debe asegurar su supervivencia, modificando la respuesta inmune materna. En experimentos realizados con cultivos de células endometriales de vaca (línea celular: BEND), sometidos a $100 \mathrm{ng} / \mathrm{ml}$ de INFt por 24 horas, se encontró que se secretaba una proteína conocida como Factor Inhibitorio de Migración de Macrófagos (MIF), el cual se encarga de impedir la salida de macrófagos desde los capilares sanguíneos hasta el lumen uterino y evitar agresiones al embrión (4).

Remodelación endometrial. El INFt también estimula una remodelación endometrial local es decir, entre el centro del cuerno uterino y el cuerpo, lugar de preferencia para el inicio de la implantación (29). Dicho proceso es un complejo mecanismo regulado por el INFt y la $\mathrm{P}_{4}$. En cultivos de células BEND, sometidos a dosis exógenas de INFt, se demostró que existe una clara relación entre el aumento de la apoptosis y la presencia de INFt (30). Se asume que fisiológicamente, esta relación daría a lugar a una renovación marcada del endometrio, lo que facilitaría el proceso de implantación (31). Además, el INFt induce la expresión de la familia de las enzimas catepsinas, proteínas lisosomales encargadas de degradar la matriz extracelular (32).

\section{MORTALIDAD RELACIONADA CONBRIONARIA CARENCIAS DE LA RECEPTIVIDAD UTERINA}

La mortalidad embrionaria constituye un problema reproductivo que produce grandes pérdidas económicas a los productores, debido en parte a que es multicausal y a que en la mayoría de ocasiones se presenta sin alterar la duración del ciclo estral (33). La mortalidad embrionaria relacionada con fallas en el establecimiento del ambiente embriotrófico puede resultar si hay defectos intrínsecos en el embrión, en el balance hormonal materno o asincronía entre la madre y el embrión, es decir que la señal de reconocimiento materno no se de en el momento indicado (6). La mayor parte de los embriones mueren entre los días 8 y 17 de la gestación $(21,34)$, por lo que no se presenta en forma aparente ningún disturbio en la duración del ciclo estral (13). El embrión 
puede morir al producir pocas cantidades de INFt y no lograr inhibir la luteólisis, por fallas genómicas o por tener algún grado de degeneración al momento en que debe darse la señal de reconocimiento $(6,34)$. Si la falla en el ambiente embriotrófico tiene causas maternas, puede deberse a desequilibrios hormonales. Algunas vacas repetidoras de calores tienen menores niveles de $\mathrm{P}_{4}$, por lo cual se han implementado técnicas como el suministro de $\mathrm{P}_{4}$ exógena o la inducción de cuerpo lúteo accesorio para aumentar la tasa de preñez (34). Esto fue demostrado al realizar biopsias endometriales a vacas con ciclos normales y a repetidoras de celos y relacionarlo con los perfiles hormonales. Se demostró que hubo cambios histológicos anormales en el útero de las vacas repetidoras con menores niveles de $P_{4}$ durante su fase luteal. Por ejemplo, no se establece remodelación del útero y hay disminución marcada de las secreciones glandulares endometriales, lo cual dificultaría los procesos de migración, desarrollo e implantación del conceptus (35). Por otro lado, también pueden presentarse carencias en el ambiente embriotrófico cuando no existe una correcta sincronía entre la madre y el conceptus, disminuyendo la tasa de preñez (34). Por tales razones, se considera que la relación entre la $\mathrm{P}_{4}$ y el INFt, que se establece en la preñez temprana, es interdependiente en cuanto a sus funciones biológicas porque para que se lleve a cabo exitosamente el proceso de gestación, se requiere que tanto la $\mathrm{P}_{4}$ como el INFt se encuentren en momentos, tiempos y cantidades adecuadas, de manera que se cumplan todos los eventos fisiológicos necesarios para que se establezca el ambiente embriotrófico (34).

\section{REFERENCIAS}

1. Díaz FH, Hernández A, Gil A. Morfología endometrial y niveles de $\mathrm{P}_{4}$ en el tejido uterino durante el ciclo estral de vacas cebú. Rev Med Vet Zoot 1986; 39: 15-27.

2. Callejas, S. Fisiología del Ciclo Estral Bovino. En: Palma G, editor. Biotecnología de la reproducción. Buenos Aires (Argentina): Instituto Nacional de Tecnología Agropecuaria INTA; 2001.

3. Peiris ID, Grewal TS, Jeacock MK, Savva D, Shepherd DAL. Effect of a novel recombinant bovine interferon and trophoblast secretory products on protein metabolism by endometrial explants from cattle and sheep. Res Vet Sci 1998; 64:79-83.

4. Wang B, Goff A. Interferon-ô stimulates secretion of macrophage migration inhibitory factor from bovine endometrial epithelial cell. Biol Reprod 2003; 69: 1690-1696.
5. Spencer TE, Johnson GA, Burghardt RC, Bazer FW. Progesterone and placental hormone actions on the uterus: Insights from Domestic Animals. Biol Reprod 2004; 71: 2-10.

6. Hansen PJ. Embryonic mortality in cattle from the embryos perspective. J Anim Sci 2002.80 Suppl: 33-44.

7. Roberts RM, Xie S, Mathialagan N. Maternal recognition of pregnancy. Biol Reprod 1996; 54: 294-302.

8. Rabbani M, Rogers PAW. Role of vascular endothelial growth factor in endometrial vascular events before implantation in rats. Reproduction 2001; 122: 85-90.

9. Ding YQ, Zhu LJ, Bagchi MK, Bagchi IC. Progesterone stimulates calcitonine gene expression in the uterus during implantation. Endocrinology 1994; 135: 2265-2274. 
10. Kayser JPR, Kim JG, Cerny RL, Vallet J. Global characterization of porcine intrauterine proteins during early pregnancy. Reproduction 2006; 132: 379-388.

11. Mitko K, Ulbrich SE, Wenigerkind $H$, Sinowatz F, Blum H, et. al. Dynamic changes in messenger RNA profiles of bovine endometrium during the oestrus cicle. Reproduction 2008; 135: 225-240.

12. Hernández, A. Lecturas sobre reproducción bovina. Tomo III. Aspectos morfofisiológicos de la implantación. Bogotá, Colombia: Universidad nacional de Colombia. Facultad de medicina veterinaria y zootecnia; 1995.

13. Lee RSF, Wheeler TT, Peterson AJ. Large format, two dimensional poliacrylamide gel electrophoresis of ovine periimplantation uterine luminal fluid proteins: identification of aldose reductase, cytoplasmic actin, and transferring as conceptussynthesized proteins. Biol Reprod 1998; 59: 743-752.

14. Abdi-Dezfuli F, Poyser NL. Hormonal controls of proteins synthesized and secreted by guinea-pig endometrium. J Reprod Fertil 1993; 97: 179-188.

15. Lee K, Jeong J, Tsai M, Tsai S, Lydon JP, et. al. Molecular mechanisms involved in progesterone receptor regulation of uterine function. J Steroid Biochem Mol Biol 2006; 102, 41-50.

16. Cullinan-Bove K, Koos R. Vascular endothelial growth factor/ vascular permeability factor expression in the rat uterus: rapid stimulation by estrogen correlates with estrogeninduced increases in uterine capillary permeability and growth. Endocrinology 1993; 133: 829-837.

17. Wang CK, Robinson RS, Flint AP, Mann GE. Quantitative analysis of changes in endometrial gland morphology during bovine oestrus cycle and their association whit progesterone levels. Reproduction 2007; 134: 365-371.

18. Niswender GD, Juengel JL, McGuire WJ, Belfiore CJ, Wiltbank MC. Luteal function: the estrus cycle and early pregnancy. Biol Reprod 1994; 50: 239-47.

19. Olivera M. Vías implicadas en la luteólisis bovina. Rev Col Cienc Pec 2007; 20: 387-393.

20. Kombe A, Sirois J, Goff AK. Prolonged progesterone treatment of endometrial epithelial cells modifies the effect of $E_{2}$ on their sensitivity to oxytocin. Steroids 2003; 68: 651-658.

21. Lessey BA, Yeh Y, Castelbaum AJ, Fritz MA. Endometrial progesterone receptors and markers of uterine receptivity in the window of implantation. Fertil Steril 1996; 65: 477-83.

22. Thatcher WW, Meyer MD, DanetDesnoyers G. Maternal Recognition of pregnancy. J Reprod Fertil 1995; 49: $15-28$.

23. Ott $T L$, Zhou $Y$, Mirando MA, Stevens $C$, Harney JP, et. al. Changes in progesterone and estrogen receptor mRNA and protein during maternal recognition of pregnancy and luteolysis in ewes. J Mol Endocrinol 1993; 10: 171-183.

24. Spencer TE, Becker WC, George $P$, Mirando $M$, Olge TF, et. al. Ovine interferon-ô inhibits estrogen receptor up-regulation and estrogen-induced luteolysis in cyclic ewes. Endocrinology 1995; 136: 4932-4944.

25. Gazeloglu A, Subramaniam P, Michel $F$, Thatcher WW. Interferon-t induces degradation of prostaglandin $\mathrm{H}$ synthase- 2 messenger RNA in bovine endometrial cells through a transcription-dependent mechanism. Biol Reprod 2004; 71: 170-176. 
26. Vallee M, Beaudry D, Roberge C, Matte JJ, Blouin R. Isolation and differential expressed genes in conseptuses and endometrial tissue of sows in early gestation. Biol Reprod 2003; 69: 1697-706.

27. Spencer TE, Sandra O, Wolf E. Genes involved in conceptus-endometrial interactions in ruminants: insights from reductionism and thoughts on holistic approaches. Reproduction 2008; 135: 165-179.

28. Huddleston $H$, Schust DJ. Immune interactions at the maternal-fetal interface: a focus on antigen presentation. Am J Reprod Immunol 2004; 51: 283-289.

29. Umaña JA, Hernández A, Densidad capilar en el útero bovino durante la implantación. Rev ACOVEZ 1994; 19: 10-12.

30. Wang B, Xiao C, Goff AK. Progesterone-Modulated induction of apoptosis by Interferon-Tau in cultured epithelial cells of bovine endometrium. Biol Reprod 2003; 68: 673-679.
31. Binelli $M$, Subramaniam $P$, Diaz $T$, Johnson G, Hansen TR, et. al. Bovine interferon-t stimulates the janus kinase-signal transducer and activator of transcription pathway in bovine endometrial epithelial cells. Biol Reprod 2001; 64: 654-665.

32. Song G, Spencer TE, Bazer FW. Progesterone and interferon t regulate cystatin $\mathrm{C}$ in the endometrium. Endocrinology 2006; 147: 3478-3483.

33. Hernández A. Métodos de evaluación de la mortalidad embrionaria. Rev Vet al día 1995; 1 : 28-30.

34. Thatcher WW, Guzeloglu A, Mattos R, Binelli M, Hansen TR. et. al. UterineConceptus interactions and reproductive failure in cattle. Theriogenology 2001; 56: 1435-1450.

35. Ohtani S, Okuda K. Histological observation of the endometrium in repeat breeder cows J Vet Med Sci 1995; 57: 283-286. 